\title{
Sugammadex Use in a Patient with Wolff-Parkinson-White (WPW) Syndrome
}

\author{
Sevtap Hekimoğlu Şahin, İlhan Öztekin, Aytuna Kuzucuoğlu, Ayça Aslanoğlu
}

Department of Anesthesiology and Reanimation, Trakya University Faculty of Medicine, Edirne, Turkey

Background: Wolff-Parkinson-White (WPW) syndrome is a disease associated with episodes of supraventricular tachycardia and ventricular pre-excitation or atrial fibrillation. WPW is characterized by an aberrant electrical conduction pathway between atria and ventricles.

Case Report: The major anesthetic problem connected with WPW syndrome is the risk of tachyarrhythmias due to accessory pathway. Therefore, it has been proposed that the aim of anesthetic management should be the avoidance of tachyarrhythmia and sympathetic stimulation. Sugammadex was administered as a neu- romuscular reversal agent in this case. To our knowledge, this is the first case report of sugammadex use in a patient with WPW. This report presents a case of general anesthesia management in a patient with WPW syndrome.

Conclusion: We think that it is appropriate to use sugammadex to reverse rocuronium for the prevention of sudden hemodynamic changes in patients with WPW who underwent general anesthesia.

Keywords: General anesthesia, sugammadex, WolffParkinson-White syndrome
Wolff-Parkinson-White (WPW) syndrome is a disease associated with attacks of supraventricular tachycardia (SVT) and ventricular pre-excitation or atrial fibrillation (AF). Therefore, WPW syndrome is usually known as pre-excitation syndrome (1-3). WPW is characterized by an aberrant electrical conduction pathway between the atria and ventricles. The major anesthesia problem connected with WPW syndrome is the risk of tachyarrhythmias due to the accessory pathway (1-3). Therefore, it has been proposed that the aim of anesthetic management should be the avoidance of tachyarrhythmia and sympathetic stimulation. Anesthesia induction, maintenance and decurarization is important for the use of anesthetic agents. It is necessary to avoid stimuli when using muscle relaxants to antagonize sympathetic activation. Sugammadex was administered as a neuromuscular reversal agent in this case. Although sugammadex has been seen as a suitable agent for this purpose, it has not been used for WPW syndrome in the literature. This report presents a case of general anesthesia management in a patient with WPW syndrome.

\section{CASE PRESENTATION}

A 51 year-old, $100 \mathrm{~kg}$, male patient with WPW syndrome was scheduled for inguinal hernia repair under general anesthesia. The patient was diagnosed with WPW syndrome two years ago and was not taking any medication. However, the patient had symptoms of panic attacks and was using paroxetine (tb $20 \mathrm{mg} /$ day). He had undergone general anesthesia once, twenty years ago. Evaluation by electrocardiography in the cardiology clinic revealed delta wave at the beginning of the QRS complex. Preoperative blood analysis and

This paper was presented as poster at the 47 National Congress of Turkish Society of Anesthesiology and Reanimation, 20-24 November 2013, Antalya, Turkey.

Address for Correspondence: Dr. Sevtap Hekimoğlu Şahin, Department of Anesthesiology and Reanimation, Trakya University Faculty of Medicine, Edirne, Turkey Phone: +90533 3545484 e-mail: sevtaphekimoglu@mynet.com

Received: 17.03.2014 Accepted: 15.11.2014 • DOI: 10.5152/balkanmedj.2014.15155

Available at www.balkanmedicaljournal.org 
serum electrolytes were all within normal limits. A defibrillator was kept ready for potential attacks of tachyarrhythmia. Written informed consent was obtained from the patient for this study. Intramuscular midazolam $(0.07 \mathrm{mg} / \mathrm{kg})$ was administered as premedication 45 minutes before the operation. He was monitored with measurements of peripheral oxygen saturation $\left(\mathrm{SpO}_{2)}\right.$, electrocardiograms (leads II, V1), cutaneous temperature (T), and noninvasive blood pressure (NIBP) assessments in the operating room. His heart rate (80 beats $/ \mathrm{min})$, blood pressure $(135 / 55 \mathrm{mmHg})$ and body temperature $\left(36.6{ }^{\circ} \mathrm{C}\right)$ were also recorded. Anesthesia was induced by $0.5 \mu \mathrm{g} / \mathrm{kg}$ tramadol, $2.5 \mathrm{mg} / \mathrm{kg}$ propofol, and 0.6 $\mathrm{mg} / \mathrm{kg}$ rocuronium, intravenously. Tracheal entubation was performed uneventfully. Heart rate reached its peak at 108 beats $/ \mathrm{min}$ in one minute after entubation, then i.v $0.25 \mathrm{mcg} /$ $\mathrm{kg}$ remifentanil was applied. Maintenance was achieved using sevoflurane $1 \mathrm{MAC}$ in a 50/50\% air: oxygen mixture. No respiratory or hemodynamic problems were not seen during the surgery time of 120 minutes. Sugammadex $(2 \mathrm{mg} /$ $\mathrm{kg}$ ) was administered to reverse neuromuscular block while spontaneous breathing returned after the end of surgery. The tracheal tube was extubated following sufficient spontaneous breathing. The patient was taken to his room in a good general condition.

\section{DISCUSSION}

Wolff-Parkinson-White syndrome is a rare cardiac disorder involving an aberrant electrical conduction pathway between the atria and ventricles. Life-threatening arrhythmias such as paroxysmal SVT or VT have been reported to occur in WPW syndrome in the literature. The incidence of WPW in the general population is between $0.1 \%$ and $3 \%(1-5)$.

The management of anesthesia is used to prevent any factor that increases sympathetic activity such as anxiety, pain, stress response to intubation, hypovolemia and lighter plane of anesthesia $(2,3)$. In addition, anti-arrhythmic drugs such as digoxin and verapamil should be avoided, because these drugs increase the anterograde conduction of cardiac impulses by the accessory pathway $(2,3)$.

Wolff-Parkinson-White syndrome has been reported under either general or regional anesthesia. Regional anesthesia is the preferred technique over general anesthesia to avoid multi-drug administration, harmful stimuli of laryngoscopy and intubation $(2,3)$. Sympathetic blockade can lead to sudden bradycardia and hypotension in spinal anesthesia. However, spinal anesthesia provides rapid onset with a reduced risk of hypotension with low-dose local anesthetic drug supplemented with opioids. The vasopressors use can cause tachycardia and arrhyth- mias (4-6). The decreased atrial filling after spinal anesthesia was associated with arrhythmogenicity of the heart. Epidural anesthesia provides an added advantage of post-operative analgesia and hemodynamic stability $(1,4)$. In light of this information, neuroaxial blocks have shown detrimental effects such as SVT and hypotension on WPW syndrome in some studies (4-6). We preferred general anesthesia because our patient was symptomatic with a history of panic attacks.

Thiopentone is safe for anesthetic management in WPW syndrome. However, thiopentone has no effect on the refractory period of accessory pathway. Propofol may also be preferred in this condition $(2,3)$. Ketamine, atropine and glycopyrrolate precipitate tachycardia; therefore, we should avoid these agents during anesthesia $(2,3)$. Isoflurane and sevoflurane have no effect on atrioventricular node transmission and provide the optimal hemodynamic status $(2,3,5)$. Opioids such as fentanyl offer adequate hemodynamic stability. Rocuronium and vecuronium are cardiac stable muscle relaxants preferred over atracurium and pancuronium. Neostigmine can facilitate transmission via the accessory pathway and can cause AF with rapid ventricular rate. Mivacurium may be safe because reversal with neostigmine and glycopyrrolate are not necessary. However, mivacurium causes the release of histamine and tachycardia $(1,5)$. Sugammadex is a newly developed drug and it used to reverse rocuronium- or vecuronium-induced neuromuscular blockade. Sugammadex can be given for instant reversal and may reverse deep blockade; its use would avoid the possible serious side effects of succinylcholine. In addition, sugammadex may reverse neuromuscular blockade more rapidly and predictably than equivalent drugs. In patients with severe heart disease undergoing non-cardiac surgery, sugammadex does not have any hemodynamic effects and it does not cause the prolongation of QT interval (7). Hemmerling et al. (8) reported that sugammadex provides a unique opportunity for cardiac anesthesiologists. The reliable and fast reversal of neuromuscular blockade is available without any important side-effects for this high-risk population of patients. Because reversal with sugammadex does not work through cholinergic mechanisms, sugammadex is seen to be used a safe drug, in the same way as anticholinesterase is seen by clinicians for reversing rocuronium and vecuronium. Previous studies demonstrated the general anesthesia management in patients with WPW syndrome $(2,4)$. However, sugammadex use in a patient with WPW syndrome has not been presented.

No adverse reactions of sugammadex are known under general anesthesia, although there are various cases in the literature of QT prolongation by this drug. Kam et al. (9) reported that $4 \mathrm{mg} / \mathrm{kg}$ sugammadex does not cause clinically significant QTc interval prolongation versus placebo when used with 
propofol or sevoflurane. However, Osaka et al. (10) reported that sugammadex caused atrioventricular block. In their study, second-degree atrioventricular block (Wenckebach type) developed after a dose of sugammadex before tracheal exubation. This atrioventricular block was changed in to first degree atrioventricular block over 3 minutes and the normal sinus rhythm was seen after a few minutes. We did not see these adverse effects of sugammadex in our case.

We think that it is appropriate to use sugammadex to reverse rocuronium for the prevention of sudden hemodynamic changes in patients with WPW who underwent general anesthesia.

\section{Ethics Committee Approval: N/A.}

Informed Consent: Written informed consent was obtained from the patient.

Peer-review: Externally peer-reviewed.

Author contributions: Concept- S.H.Ş., İ.Ö.; Design - S.H.Ş., İ.Ö., A.K., A.A.; Supervision - S.H.Ş., İ.Ö., A.K., A.A.; Resource S.H.Ş., İ.Ö., A.K., A.A.; Materials - S.H.Ş., İ.Ö.; Data Collection \&/ or Processing - S.H.Ş., İ.Ö.; Analysis \&/or Interpretation - S.H.Ş., İ.Ö., A.K., A.A.; Literature Search - S.H.S.., İ.Ö., A.K., A.A.; Writing - S.H.Ş., İ.Ö., A.K., A.A.; Critical Reviews - S.H.Ş., İ.Ö., A.K., A.A.

Acknowledgements: The author would like to thank to all personnel for their valuable help to the patients.

Conflict of Interest: No conflict of interest was declared by the authors.

Financial Disclosure: The authors declared that this study has received no financial support.

Editor-in-chief's note: One of the authors of this article, Sevtap Hekimoğlu Şahin is the member of the editorial board of Balkan Medical Journal. However, she did not take place at any stage on the editorial decision of the manuscript.

\section{REFERENCES}

1. Kabade SD, Sheikh S, Periyadka B. Anaesthetic management of a case of Wolff-Parkinson-White syndrome. Indian J Anaesth 2011;55:381-3. [CrossRef]

2. Rahul S, Patel R, Dewoolkar. Anaesthetic management of WPW Syndrome. Internet J of Anaesthesiology 2006;11:2.

3. Hines RL, Marschall KE. Abnormalities of Cardiac Conduction and Cardiac Rhythm. In: Stoelting RK, Dierdorf SF, editors. Anesthesia and co-existing disease. 5th ed. Philadelphia: ChurchillLivingstone; 2008:pp.72-3.

4. Chhabra A., Trikha A., Sharma N. Unmasking of benign WPW syndrome under general anaesthesia. Indian J Anaesth 2003;47: 208-11.

5. Sahu S, Karna ST, Karna A, Lata I, Kapoor D. Anaesthetic management of Wolff-Parkinson-White syndrome for hysterectomy. Indian J Anaesth 2011;55:378-80. [CrossRef]

6. Okamoto T, Minami K, Shiraishi M, Ogata J, Shigematsu A. Repeated supraventricular tachycardia in an asymptomatic patient with Wolff-Parkinson-White syndrome during Cesarean delivery. Can J Anaesth 2003;50:752-3. [CrossRef]

7. Dahl V, Pendeville PE, Hollmann MW, Heier T, Abels EA, Blobner M. Safety and efficacy of sugammadex for the reversal of rocuronium-induced neuromuscular blockade in cardiac patients undergoing noncardiac surgery. Eur J Anaesthesiol 2009;26:87484. [CrossRef]

8. Hemmerling TM, Zaouter C, Geldner G, Nauheimer D. Sugammadex. A short review and clinical recommendations for the cardiac anesthesiologist. Ann Card Anaesth 2010;13:206-16. [CrossRef]

9. de Kam PJ, Grobara P, Dennie J, Cammu G, Ramael S, JagtSmook ML, et al. Effect of sugammadex on QT/QTc interval prolongation when combined with QTc-prolonging sevoflurane or propofol anaesthesia. Clin Drug Investig 2013;33:545-51. [CrossRef]

10. Osaka Y, Shimada N, SatouM, Masuda T, Ando T, Kozono Y, et al. A case of atrioventricular block (Wenckebach type) induced by sugammadex. J Anesth 2012;26:627-8. 